\title{
A Study of False Implications in Advertisement
}

\author{
Yue Zhu ${ }^{\text {a }}$ \\ Xi'an Peihua University, Xi'an, Shaanxi 710125, China. \\ a441317657@qq.com
}

Keywords: advertisement; Cooperative Principle; inferences; schemata; false implications.

\begin{abstract}
Advertisement plays a dominant role in transmitting information. Some advertisers rack their brains to make a profitable business at the expense of consumers. With the framework of Cooperative Principle, inferences and schemata, this paper examines how the advertiser might take advantage of language to exploit our tendency to accept false implications.
\end{abstract}

\section{Brief Introduction about Advertisement}

What is an advertisement? We can approach it from different perspectives. However, the etymology may shed light on its nature. The root of the word "advertisement" comes from the Latin word "advertere", meaning "a means used to draw attention from the public to something and lead them to some direction". Lund summarizes that the task of the advertiser is to "attract attention, arouse interest, stimulate desire, create conviction, and get action” (Lund, 1947).

Unlike the face-to-face communication, there is no direct interaction between the advertiser and its audiences at the very time of linguistic production. However, advertising communication is an audience-centered process. To invite audiences' attention and make a lasting impression, the advertiser resorts to plenty of vehicles. Although visual and aural content or designs have the access to the advertisement and exert a great impact on consumers, it is language that helps people to identify a product and remember it. Language is the most effective way the advertiser adopts to influence people and their consuming behaviors.

The ultimate goal of the advertisement is to persuade the prospective consumers into purchasing the products or services. The advertiser employs language in performing the persuasive function. This is especially favorable for some cunning advertisers, who skillfully give false impression on customers and mislead them into astray, for Harris (1977) found that people were not very good at distinguishing between claims that were directly asserted and those that were implied (Carroll,1999).

\section{Cooperative Principle and Maxims}

Grice (1975a, 1975b) proposes that all speakers, regardless of their cultural background, adhere to a basic principle governing conversation, which he termed the cooperative principle (CP). That is, make your conversational contribution such as is required, at the stage at which it occurs, by the accepted or direction of the talk exchange in which you are engaged. It can be fleshed out by the following aspects:

Quantity

1. Make your contribution as informative as is required (for the current purposes of the exchange).

2. Do not make your contribution more informative than is required.

Quality

Try to make your contribution one that is true.

1. Do not say what you believe to be false.

2. Do not say that for which you lack adequate evidence.

Relation

Be relevant.

Manner

Avoid obscurity of expression. 
1. Avoid ambiguity.

2. Be brief.

3. Be orderly. (ibid.: 45-46)

We assume that participants in a conversation will cooperate with each other when making their conversations. However, if the speaker is cooperative but deliberately violates one of the maxims, he is attempting to convey some additional information. This is where conversational implicature or inference emerges.

The advertiser should follow cooperative principle in a conversation. Whereas, some sly advertisers intend to violate their statements, in order to transmit much more information, attract attention and manipulate the mentality of consumers. Because advertisers are prevented, on legal grounds, from making false statements on their products, but making false implicatures is less dangerous. For an advertiser's, implied messages are extremely attractive because they can create the same impression as explicit messages without the same legal repercussions (Carroll, 1999).

\section{Analysis of the Flouting of Maxims in Advertisement}

Many advertisements, with this method, possess original ideas and aesthetic content and subconsciously entertain people to their hearts' content. To appreciate them is indeed an exhilarating experience. But this paper stresses the negative aspect, of how the advertiser makes the blurred impression to give rise to potential deception.

\subsection{Flouting of Maxim of Quantity}

Maxim of quantity requires the sufficient information in advertisement, for too more appears prolix, multi-centers and do not contribute to memory for consumers, while too less can not make the content explicit or appeal the audience. Due to limited time, the advertiser should transmit the succinct information of highest quality. Nevertheless, enormous advertisements are fraught with violation of maxim of quantity.

Certain heating system claims that it enables the ambient temperature reach above 25.C, without mentioning the prerequisite is within the room of $10 \mathrm{~m} 2$. On account of less information, the consumer in desperate will be misled in purchasing the counterfeit product, only find they are duped. The consequence results from overly violating the flouting of quantity with insufficient information.

Sometimes, what the advertiser omits is some key and detailed words which are crucial for the comprehension, thus result in misleading a mass of people and promoting sales. Such a trick frequents in the mobilephone at a discount. Siemens X model prices 1099! The standard price is about 1200 then. Those who read it rush into purchase. This belongs to the typical trap in the circle of mobilephone. The "mobile phone" referred, in the light of the insider, has no accessories, such as earphone and battery. The majority of consumers are not aware of the truth, only care about the cheap price. In principle, it is the obligation of advertiser to provide adequate amount of information in helping consumers correctly comprehend the message, however, this ad. leaves out the essential words about the nature of "mobile phone" to cause consumers to draw false inferences.

The violation also stands out in medical and health product ads. These ads target a particular group who need hope in advertising. The advertiser cheats customers by saying that their products are excellent without any secondary function and intentionally conceal the contraindications. For example, some beauty products catch the attention of women by saying if they using these products they will be younger and whiter and even giving some false examples to attract their attention. While it turns out to be useless or even worse. Some consumers even loss their previous health. Other sorts of these ads supply redundant information. Plenty of ads widely publicize the necessity for calcium and zinc supplement, without mentioning the consequences of too much of them.

\subsection{Flouting of Maxim of Quality}

The advertiser often caters to the psychology of consumers by the so-called celebrity or authority effect. Sometimes these well-known people claim that they have used the product, but how many of them have indeed used it? If they actually do not use it at all, they apparently flout the maxim of quality by claiming what lacks adequate evidence. Freckle with a magic solution, the self-confidence 
and performance are washing back.Such a product developed by the United States from certain experts appear frequently in various places on the TV screens, advertising in a familiar middle-aged female star in her own personal experience to display the effect of the product, and then show many other female consumers to use the product freckle success story. But according to the investigation of the journalist, many consumers complain that it does not remove freckle, instead they are allergic to the product and their faces appear many red knots.

Another normal phenomenon is employed by the statistic and scientific proof. Certain tonic has the following illustration. Through 8 doctors, 48 scientists, 100 scientific practices and 10 years great efforts ultimately manufacture the rare high-tech product---Calcium-energy. We just can't help thinking whether such an ordinary product requires so many experts and lengthy time. Maybe the inducement is where the rub is.

\subsection{Flouting of Maxim of Relation}

It is controversial to talk about the exploitation of relation. Grice (1975) notes that there may be some overlap between the second Quantity maxim and the maxim of Relation. The excessive information will be something irrelevant.

A: What on earth has happened to the roast beef?

$\mathrm{B}$ : The dog is looking very happy. (Levinson, 2001)

If one crafty advertiser applies the model into practice, many victims will be bound to arise. Although there is no direct relation in the ad., the audience could infer that the beef must be considerably tempting, for the dog reveals the satisfaction.

\subsection{Flouting of Maxim of Manner}

It requires the perspicuous expressions. While, one way most the advertiser employs is to create vague impression, either by fuzzy words or by deceptive and blurred concepts.

The ad: Milk has something for everybody. "Something" is ambiguous, because it can be accounted for "something good" as well as "something harmful". But in most instances, what consumers think about is the positive aspect subconsciously, thus the whole sentence could be explained as" Milk is good for everybody”. If the consumer is allergic to this sort of milk, he'll find he is cheated.

Good Career. Job Opportunities. This ad. invites applications for jobs. It is very attractive, for anyone who wants to succeed must be in want of a potential job. But to what degree does it belong to "good career" there is no exact definition.

A meal for two for $£ 2.99$ each. Any medium feast pizza and regular salad for only $£ 5.98$. It is a promotion ad from Pizza Hut. In virtue of blurred information, it deceives many consumers, who takes it for granted that everyone pays $£ 2.99$, then each of them will obtain a portion of pizza and salad. On the contrary, the official explanation is like this: They could only share one portion with each other. Obviously, they only knew the truth after they had been cheated.

At large, the division is pretty subjective. In most cases, these four maxims functions simultaneously and overlap with each other.

\section{Inferences and Schemata}

The literal meaning of a sentence which the speaker actually utters and the concept he intends to express are not always consistent. It is inferences which bridge the gap. From a communication standpoint, an inference is a proposition in the underlying discourse structure that is intended but not explicitly expressed by the author and thus must be drawn by the reader (Carroll, 1999). Carroll cited Brandsford's experiment to demonstrate that people's tendency to make false recognition errors due to this limitation. The obtained inferences are mainly based on reader's general knowledge of the world stored in schemata, and it can be subconsciously activated in the course of comprehension. A schema is a structure in semantic memory that specifies the general or expected arrangement of a body of information (Carroll, 1999). What the reader stored is not the specific words or phrases, but the general meaning. In the process of comprehension, the background knowledge determines to what degree people comprehend new events. 
The cunning advertisers take advantage of inferences and schemata to cheat consumers to accept false implications. The real intention is not explicitly mentioned. They only leave out blurred information which they think consumers will comprehend according to the conventionalized knowledge, because it belongs to optimal relevance and can be easily activated. Nevertheless, advertisers provide another unexpected explanation. Since the wrong comprehension is inferred by consumers themselves, they can't accuse the advertiser.

Let's look back to previous examples. The advertiser purposely conceals the scope of heating system - within the room of $10 \mathrm{~m} 2$. The stereotyped schemata tell consumers that it can be worked in any situation. It is their own inferences which lead to be cheated; In most people's eye, the famous celebrities enjoy high prestige and deserve to be trusted, and what they say must be true. So consumers believe the product must be very efficient. Their prior knowledge misleads them to infer the function of the product freckle. In fact, these celebrities belong to ordinary people. They are likely to tell lies as well. Even if the product functions for them, it doesn't mean it can work for others; The roast beef and the expression of dog have no intrinsic relationship, but consumers suppose the advertiser can't transmit irrelevant information, the happy dog illustrates the food is delicious. Their improper inferences commit errors; Generally speaking, it is very natural for two people to enjoy meal together, Pizza Hut just makes use of people's common sense to deceive consumers, so people are less possible to infer they could only share one portion with each other.

To be frank, it is consumers themselves who automatically infer the wrong information following the logical convention. Advertisers don't claim the false message overtly. They just avail themselves of loopholes to mislead consumers.

\section{Summary}

With the framework of Cooperative Principle, inferences and schemata, this paper examines how the advertiser conveys the potential deceptive information which in turn misleads the consumers. In fact, the advertisement is a beneficial vehicle connecting the advertiser and consumers. It should steer in a healthy and steady course.

\section{References}

[1]. Carroll, David. Psychology of language 3 ed. Pacific Grove: Brooks/Cole publishing company. 1999:146, 163,169

[2]. Grice, H. P. Logic and conversation. Cambridge: Harvard University.1975:45-46

[3]. Levinson, S.C. Pragmatics. Cambridge: Cambridge University Press. 2001:126

[4]. Lund. English in advertising: A linguistic study of advertising in Great Brain. London: Longman.1947:83

[5]. Promotional Offer, Pizza Hut, Feb, 1991, Lothian, Britain 